University of Wollongong

Research Online

Faculty of Science, Medicine and Health -

Papers: Part B

Faculty of Science, Medicine and Health

$1-1-2019$

\title{
Divergent gold-catalysed reactions of cyclopropenylmethyl sulfonamides with tethered heteroaromatics
}

\author{
Melanie A. Drew \\ University of Wollongong, mpearsal@uow.edu.au \\ Sebastian Arndt \\ Heidelberg University \\ Christopher Richardson \\ University of Wollongong, crichard@uow.edu.au \\ Matthias Rudolph \\ Heidelberg University \\ A. Stephen K. Hashmi \\ Ruprecht-Karls-University Heidelberg
}

See next page for additional authors

Follow this and additional works at: https://ro.uow.edu.au/smhpapers1

\section{Publication Details Citation}

Drew, M. A., Arndt, S., Richardson, C., Rudolph, M., Hashmi, A. K., \& Hyland, C. J. (2019). Divergent goldcatalysed reactions of cyclopropenylmethyl sulfonamides with tethered heteroaromatics. Faculty of Science, Medicine and Health - Papers: Part B. Retrieved from https://ro.uow.edu.au/smhpapers1/1037

Research Online is the open access institutional repository for the University of Wollongong. For further information contact the UOW Library: research-pubs@uow.edu.au 


\title{
Divergent gold-catalysed reactions of cyclopropenylmethyl sulfonamides with tethered heteroaromatics
}

\author{
Abstract \\ Cyclopropenylmethyl sulfonamides with tethered heteroaromatics have been demonstrated to undergo \\ divergent gold-catalysed cyclisation reactions. A formal dearomative $(4+3)$ cycloaddition takes place with \\ furan-tethered substrates, yielding densely functionalised 5,7-fused heterocycles related to the bioactive \\ curcusone natural products. Indole-tethered substrates display divergent reactivity giving biologically \\ important tetrahydro- $\beta$-carbolines via a Friedel-Crafts mechanism.

\section{Publication Details} \\ Drew, M. A., Arndt, S., Richardson, C., Rudolph, M., Hashmi, A. K. \& Hyland, C. J.T. (2019). Divergent gold- \\ catalysed reactions of cyclopropenylmethyl sulfonamides with tethered heteroaromatics. Chemical \\ Communications, 55 (93), 13971-13974.

\section{Authors} \\ Melanie A. Drew, Sebastian Arndt, Christopher Richardson, Matthias Rudolph, A. Stephen K. Hashmi, and \\ Christopher J. T Hyland
}




\section{Divergent Gold-catalysed Reactions of Cyclopropenylmethyl Sulfonamides with Tethered Heteroaromatics.}

Received 00th January 20xx, Accepted 00th January 20xx

DOI: $10.1039 / x 0 x \times 00000 x$

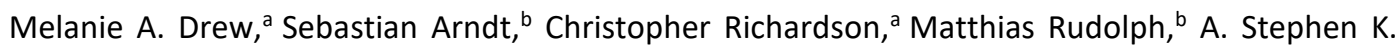
Hashmi, ${ }^{*, b}$ and Christopher J. T. Hyland*,a
Cyclopropenylmethyl sulfonamides with tethered heteroaromatics have been demonstrated to undergo divergent gold-catalysed cyclisation reactions. A formal dearomative $(4+3)$ cycloaddition takes place with furan-tethered substrates, yielding densely functionalised 5,7-fused heterocycles related to the bioactive curcusone natural products. Indole-tethered substrates display divergent reactivity giving biologically important tetrahydro- $\beta$ carbolines via a Friedel-Crafts mechanism.

Gold-catalysed reactions of cyclopropenes are emerging as powerful tools in organic synthesis. ${ }^{[1]}$ For example, their facile ring opening enables them to act as useful stable precursors to highly versatile and reactive vinyl gold carbene intermediates. ${ }^{[1-}$ 5] Cyclopropenes have also been used to study the nature of gold(I) carbene bonding. ${ }^{[6]}$ The accessibility of cyclopropenes with pendant heteroatoms has enabled new emergent methods for intramolecular trapping of these vinyl gold carbenes. Notably, Cossy, Meyer and co-workers demonstrated intramolecular cyclopropanation of mono-substituted vinyl gold carbenes generated from $\mathrm{O}$ - and $\mathrm{N}$-tethered cyclopropenes to form stereodefined bicycles. ${ }^{[3]}$ In contrast, we have shown that C1-C2-disubstituted cyclopropenylmethyl acetates undergo alternative gold-catalysed regioselective ringopening to form a disubstituted vinyl gold-carbene, which participates in a formal 1,2-acetoxy transfer to form Zacetoxydienes. ${ }^{[4,7]}$ As such, cyclopropenes provide an important, complementary, route to vinyl gold-carbenes along with other important methods from propargyl esters, ${ }^{88]}$ vinyldiazoesters ${ }^{[9 a-h]}$ and via the retro-Buchner reaction of alkenyl- or aryl-cycloheptatrienes. [9i-k] Despite straightforward synthesis via cyclopropenation of alkynes, gold-catalysed intramolecular reactions of cyclopropenes bearing heteroatom tethers at the $\mathrm{sp}^{3} \mathrm{C} 3$ position have been far less investigated than the $\mathrm{sp}^{2} \mathrm{C} 2$-tethered systems. ${ }^{[10]}$ Furthermore, to the best of our knowledge there have been no studies on trapping cyclopropene-derived vinyl gold-carbenes with pendant heteroaromatic systems. ${ }^{[11,12]}$ Lee and co-workers reported

\footnotetext{
${ }^{\text {a. }}$ School of Chemistry and Molecular Bioscience, University of Wollongong, Northfields Avenue, Wollongong, 2522, Australia

b. Organisch-Chemisches Institut, Heidelberg University, Im Neuenheimer Feld 270, 69120, Heidelberg, Germany.

Electronic Supplementary Information (ESI) available: [details of any supplementary information available should be included here]. See DOI: 10.1039/x0xx00000x
}

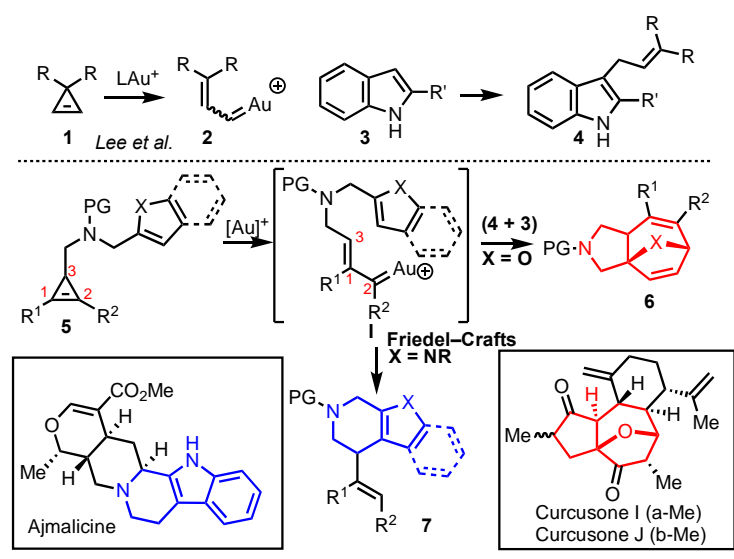

Scheme 1. Au-catalysed reactions of cyclopropenes with a pendant heteroatom

intermolecular reactions of furans and indoles (3) undergoing direct attack to vinyl gold carbenes $\mathbf{2}$ derived from the ringopening of simple cyclopropenes 1 (Scheme 1). ${ }^{[5]}$ We reasoned that employing tethered systems of type $\mathbf{5}$ should encourage the vinylogous attack of the pendant heteroaromatic based on formation of the most favoured ring-size - ultimately leading to complex heterocycles. Herein, we report the divergent reactivity of disubstituted alkenylgold carbenes I derived from cyclopropene derivatives with heteroaromatic groups tethered to a C3 aminomethyl linker (Scheme 1). Our studies reveal the first examples of vinyl gold carbenes undergoing a formal $(4+$ 3) cycloaddition with a furan tether to yield 5,7-fused heterocycles 6 . This reaction adds to the existing suite of coinage metal-catalysed $(4+3)$ cycloaddition processes, including those using allenes ${ }^{13}$ and propargyl esters. ${ }^{14}$ Crucially, when indole/pyrrole tethers are used, divergent reactivity emerges via a Friedel-Crafts process to give tetrahydro- $\beta$ carbolines 7. Heterocycles 6 are important as they are related structurally to the daphnane/ tigliane/rhamnofolane diterpenes (e.g. curcusones $\mathrm{I}$ and J) that have numerous biological activities including anti-HIV, antimicrobial, antitumour, antimalarial and neurotropic activity (Scheme 1b). ${ }^{[15,16]}$ The tetrahydro- $\beta$-carboline skeleton obtained from the indole-tethered system is also found in an array of bioactive molecules, including the antihypertensive ajmalicine. ${ }^{[17]}$ 


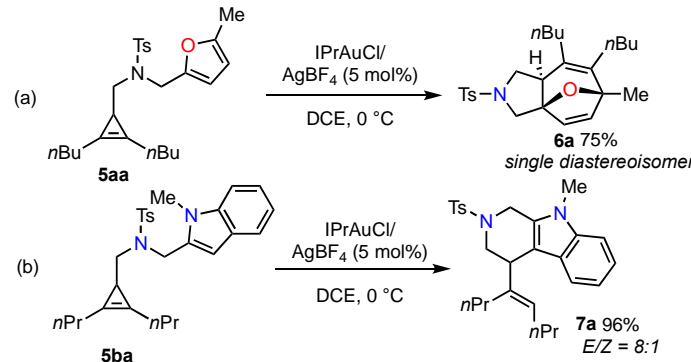

Scheme 2: Initial gold-catalysed reaction of tethered cyclopropenes

To investigate the reactivity of C3-heteroaromatic tethered cyclopropenes, a 5-methylfuran-tethered (5aa), an $\mathrm{N}$ methylindole-tethered (5ba) and a 5-methylthiophenetethered system (5c - not shown) were synthesised. ${ }^{[18]}$ Treatment of the furan-tethered cyclopropene (5aa) with the $\mathrm{NHC}$ gold catalyst system IPrAuCl/AgBF 4 provided the oxabridged 5,7-fused cycloadduct $\mathbf{6} \mathbf{a}$ as a single diastereoisomer in good yield (Scheme 2a - for optimisation see Table S1). This product arises from a formal $(4+3)$ cycloaddition between an in-situ generated vinyl gold carbene and the furan tether. Importantly, gold-phosphine catalysts and the Brønsted acid $\mathrm{HNTf}_{2}$ were incapable of effecting this transformation (see $\mathrm{SI}$ ). The $\mathrm{N}$-Me indole tethered cyclopropene $\mathbf{5 b a}$ diverged in reactivity under the same conditions to give tetrahydro- $\beta$ carboline $7 a$ in excellent yield (Scheme $2 b$ ). This latter reaction is consistent with a Friedel-Crafts process involving alkylation

Table 1. Substrate scope for the $(4+3)$ dearomative cycloaddition of cyclopropenyl furyl sulfonamides 5

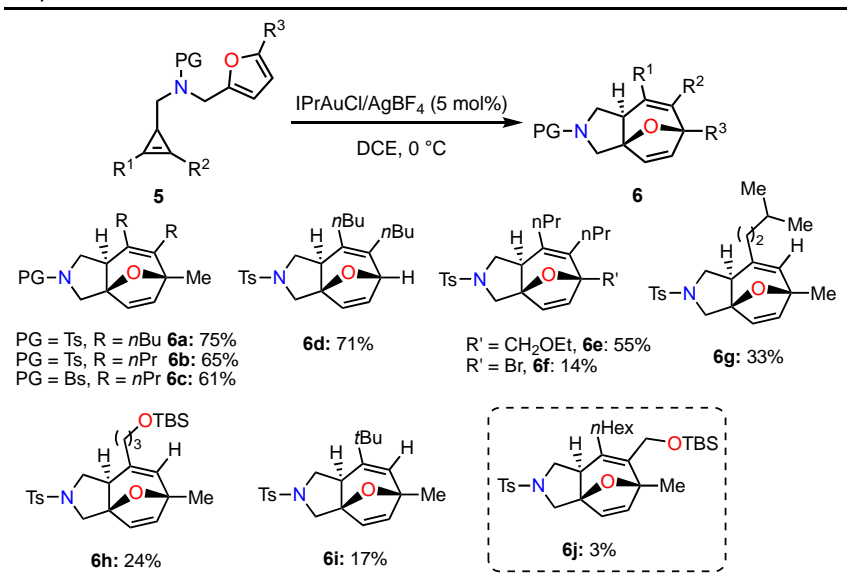

An X-ray crystal structure was obtained for heterocycle 6d (CCDC 1909426, contains the supplementary crystallographic data).

with the vinylgold carbene. Use of the more aromatic and less nucleophilic thiophene tether of derivative $5 c$ resulted in diene 8 (not shown, see SI) forming - likely via a 1,2-H shift and subsequent deauration. With the reactivity pattern of the tethered cyclopropenylmethyl sulfonamides established, the substrate scope for the $(4+3)$ cycloaddition was explored (Table 1). Shortening the alkyl chains $R^{1}$ and $R^{2}$ by one carbon produced heterocycle 6 b in good yield and the reaction conditions also tolerated a change in protecting group to a brosyl and provided $6 \mathrm{c}$ also in good yield. The importance of a substituent in the furan 5 -position was probed by preparing cyclopropenyl furyl sulfonamide 5 ad $\left(R^{3}=H\right)$, which provided the oxa-bridged 5,7-fused heterocycle $\mathbf{6 d}$ in good yield. Cycloadduct $\mathbf{6 d}$ also provided $\mathrm{X}$-ray quality crystals that gave definitive structural assignment and relative configuration. Changing $\mathrm{R}^{3}$ to a $-\mathrm{CH}_{2} \mathrm{OEt}$ substituent gave heterocycle $6 \mathbf{e}$, however, heterocycle $\mathbf{6 f}$ was isolated in low yield, which was likely due to the

Table 2. Substrate scope for the Friedel-Crafts cyclisation of cyclopropenyl pyrrolyland indolyl-sulfonamides 5
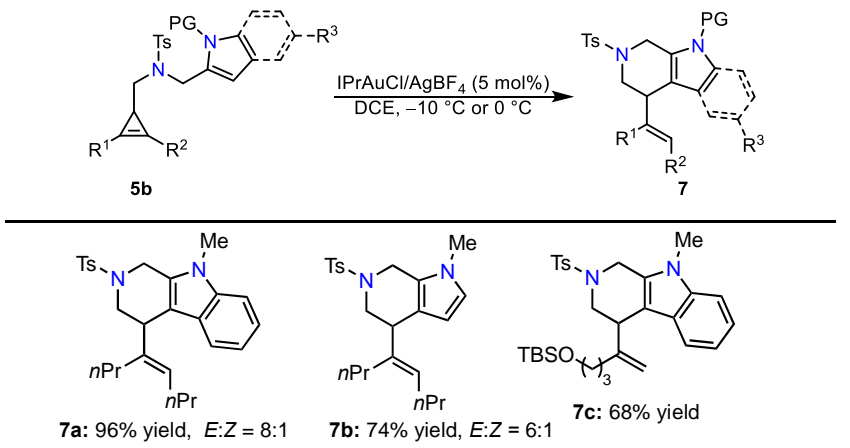

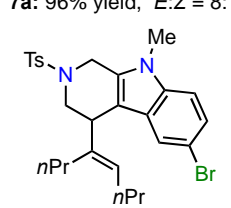

$7 \mathrm{~d}: 88 \%$ yield, $E: Z=6: 1$

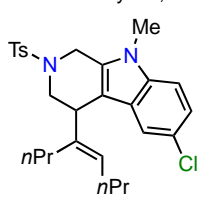

7e: $90 \%$ yield, $E: Z=7: 1 \quad 7 \mathrm{f}: 87 \%$ yield, $E: Z=6: 1$
The synthesis of $7 \mathrm{c}$ was conducted at $-10{ }^{\circ} \mathrm{C}$. An X-ray crystal structure was obtained for heterocycle 7a (CCDC 1909427 contains the supplementary crystallographic data.)

presence of an electron-withdrawing bromo-substituent in the $\mathrm{R}^{3}$ position. Unsymmetrical, mono-substituted cyclopropenyl furyl sulfonamides 5ag-5ai were investigated, although yields for the corresponding heterocycles $\mathbf{6 g}-\mathbf{6 i}$ dropped substantially which, in our previous experience, is due to the less-substituted cyclopropenes being unstable towards decomposition. The unsymmetrical, disubstituted substrates 5aj $\left(\mathrm{R}^{1}=-\mathrm{C}_{6} \mathrm{H}_{13}, \mathrm{R}^{2}=-\mathrm{CH}_{2} \mathrm{OTBS}\right)$ and $\mathbf{5 a k}\left(\mathrm{R}^{1}\right.$ $=\mathrm{Ph}, \mathrm{R}^{2}=\mathrm{Me}-$ not shown, see $\mathrm{SI}$ ) failed to produce significant amounts of the corresponding heterocycles $\mathbf{6} \mathbf{j}$ and $\mathbf{6 k}$. In the case of 5 aj the diene was the major product, likely a result of the OTBS facilitating a 1,2-H shift. The presence of two aryl substituents on the cyclopropene (5al - not shown, see SI) also prevented the cycloaddition from occurring, presumably because of the additional stabilisation of the gold carbene by the aromatic substituent resulting in a poor reactivity. The substrate scope with respect to indole and pyrrole-tethered cyclopropenes was next explored (Table 2).

The indole could also be exchanged with a pyrrole ring to produce heterocycle $\mathbf{7 b}$ in good yield. To our delight, when the monosubstituted cyclopropene example $\mathbf{5 b c}$ was reacted, heterocycle $\mathbf{7 c}$ was obtained in good yield, which contrasts with the low yield obtained for the $(4+3)$ cycloaddition reaction with the analogous furan-tethered substrate (6h). Pleasingly, we found that inductively electron-withdrawing halogens $(\mathrm{Br}$ and $\mathrm{Cl})$ in the 5position of the indole ring were well-tolerated, giving heterocycles $\mathbf{7 d}$ and $\mathbf{7 e}$ in excellent yields. Such products are (vide infra) amenable to further functionalisation through cross-coupling reactions. A benzyl protecting group for the indole was well-tolerated giving 
heterocycle $7 \mathrm{f}$ in excellent yield, however, as expected, the electronwithdrawing tosyl group shut down the reaction pathway, which we attribute to the reduced nucleophilicity of the pyrrole, resulting in diene formation. A proposed mechanism for the formation of 5,7fused heterocycles $\mathbf{6}$ from cyclopropenyl furyl sulfonamides $\mathbf{5 a}$ involves gold-activation of the electron-rich cyclopropene double bond that leads to rapid ring-opening furnishing the alkenylgoldcarbene intermediate I (Scheme 3).

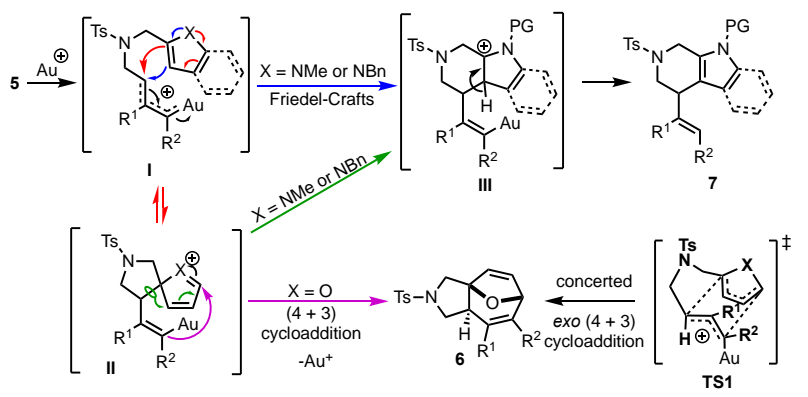

Scheme 3. Proposed mechanism for the formation of 6 and 7

Conjugate nucleophilic attack from the furan 2-position to the vinylgold carbene then forms the spirocyclic intermediate II. Nucleophilic attack of the vinyl gold onto the oxonium ion provides the observed heterocycle 6 (purple arrows) and regenerates the gold(I) catalyst. The major diastereoisomer obtained in the cycloaddition reaction matches that of the curcusone I and J natural products and also that obtained from the previously reported $\mathrm{Au}$ catalysed allene $(4+3)$ cycloaddition to furans. ${ }^{[13 b]}$ If a stepwise mechanism is operating, it is suggested that initial nucleophilic attack of the furan might be reversible, and that only one diastereoisomer of II undergoes favourable cyclisation to the observed diastereoisomer of the product. While there have been no reports of vinyl gold carbenes of type II undergoing concerted cycloaddition reactions, such a process cannot be ruled out. If a concerted pathway is occurring from I then exo TS1 would explain the relative stereochemistry of the cycloaddition product. Similar transition states have been proposed for $(4+3)$ cycloaddition reactions with allene-derived gold allylic cations stabilised by gold at the central carbon. ${ }^{[11]}$ The regioselectivity of the cycloaddition with monosubstituted cyclopropene substrates can be explained based on the preferential ring-opening to place the gold on the less substituted carbon atom. This observation matches that reported previously and our own computational studies. ${ }^{[3,4,7]}$ Two plausible Friedel-Crafts-type mechanisms for cyclopropenyl indolyl (and pyrrole) sulfonamides $\mathbf{5 b}$ are postulated (Scheme 3). [19] Each pathway invokes the alkenylgold(I) carbene intermediate $I$ as a crucial initial species by the same cyclopropene ring opening chemistry. The first proposed pathway involves attack from the nucleophilic 3-position of the indole in intermediate I (blue arrows) to generate intermediate III, which could subsequently form heterocycle $\mathbf{7}$ following re-aromatisation and protodeauration. The proposed pathway for the pyrrole-tethered system involves attack from the nucleophilic 2-position of the pyrrole ring to generate intermediate II (red arrows). A Wagner-Meerwein shift (green arrows) then provides intermediate III which, following rearomatisation and protodeauration, delivers the observed heterocycle 7.[20] In both reactions, conjugate attack on the alkenylgold carbene may be facilitated by the NHC-ligand reducing carbocation character at $\mathrm{C} 8$, combined with the formation of a more favourable 5-membered vs 7-membered ring. Chemical transformations were performed on heterocycles 6 and 7 to demonstrate their versatility. Desilylation of heterocycle $\mathbf{6 h}$ using

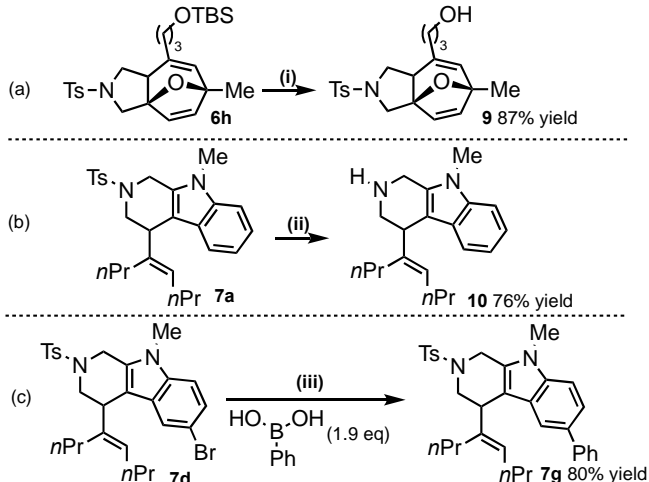

Scheme 4. Conditions: (i) TBAF (2 eq), THF, rt; (ii) Mg (50 eq), MeOH/THF (3:1), sonication; (iii) $\mathrm{Pd}(\mathrm{dppf}) \mathrm{Cl}_{2} \cdot \mathrm{CH}_{2} \mathrm{Cl}_{2}(12 \mathrm{~mol} \%), \mathrm{K}_{2} \mathrm{CO}_{3}$ (2.3 eq), dioxane: $\mathrm{H}_{2} \mathrm{O}(4: 1), 85-95^{\circ} \mathrm{C}$

TBAF in THF at rt gave the corresponding alcohol 9 in $87 \%$ yield (Scheme 4a). Tosyl de-protection with $\mathrm{Mg}$ in $\mathrm{MeOH} / \mathrm{THF}$ was successfully performed with heterocycle $7 a$ to obtain the free amine 10 in $76 \%$ yield (Scheme $4 b$ ). A Suzuki cross-coupling was carried out on $\mathbf{7 d}$ and heterocycle $\mathbf{7 g}$ was obtained in $80 \%$ yield (Scheme $4 \mathrm{c}$ ). This result proved important as the range of accessible products could be further expanded for heterocycles $\mathbf{7}$ given the vast range of commercially available boronic acids. In conclusion, the gold(I)catalysed rearrangements of cyclopropenyl sulfonamides $\mathbf{5}$ (Scheme 1) can be controlled via the identity of the tethered heterocycle. When an indole tether is present, a Friedel-Crafts reaction provides tetrahydro- $\beta$-carbolines $\mathbf{7}$ in excellent yields and good $E: Z$ selectivities. However, when a furan is present, a $(4+3)$ dearomative cycloaddition ensues to provide highly complex 5,7-fused heterocycles 6 in moderate to good yields as single diastereoisomers. To the best of our knowledge, this is the first example of a dearomatising cycloaddition to a cyclopropene-derived gold carbene. The facile synthesis of cyclopropenes of this type (three generally high-yielding steps) is an additional benefit and provides complementary substitution at $R^{1}$ and $R^{2}$ compared to the previously reported allene $(4+3)$ cycloaddition reactions. Given that these relatively simple starting materials can be transformed into highly complex heterocyclic structures that are precursors to numerous biologically active natural products, this method could represent a more efficient route for accessing these molecules. Future work is aimed at investigating longer tethers and $\mathrm{O}$-linkers in place of the $\mathrm{N}$ linkers, to expand the range of heterocycles accessible. Enantioselective variants of the two reactions and further mechanistic studies are also currently under investigation.

The authors acknowledge funding from Australian Research Council Discovery project: grant number DP180100904, the University of Wollongong and the DAAD-UA scheme

\section{Conflicts of interest}

There are no conflicts to declare.

\section{Notes and references}

1 For reviews see: a) F. Miege, C. Meyer, J. Cossy, Beilstein J. Org. Chem. 2011, 7, 717; b) G. Ernouf, J.-L. Brayer, C. Meyer, 
J. Cossy, Beilstein J. Org. Chem. 2019, 15, 333; c) M. Rubin, M. Rubina, V. Gevorgyan, Synthesis 2006, 1221; d) M. Rubin, M. Rubina, V. Gevorgyan, Chem. Rev. 2007, 107, 3117; e) Z.-B. Zhu, Y. Weib, M. Shi, Chem. Soc. Rev. 2011, 40, 5534; f) F. L. Carter, V. L. Frampton, Chem. Rev. 1964, 64, 497; g) A. Archambeau, F. Miege, C. Meyer and J. Cossy, Acc. Chem. Res., 2015, 48, 1021-1031.

2 For original research see: a) J. T. Bauer, M. S Hadfield, A.-L. Lee, Chem. Commun. 2008, 6405; b) Z. B. Zhu, M. Shi Chem. Eur. J. 2008, 14, 10219; c) C. Li, Y. Zeng, J. Wang, Tetrahedron Lett. 2009, 50, 2956; d) M. S. Hadfield, J. T. Bauer, P. E. Glen, A.-L. Lee, Org. Biomol. Chem. 2010, 8, 4090; f) P. L. Zhu, Z. Zhang, X. Y. Tang, I. Marek, M. Shi, ChemCatChem 2015, 7, 595; g) P. L. Zhu, X. Y. Tang, M. Shi, ChemistryOpen 2016, 5, 33-37; h) F. F. Mulks, S. Faraji, F. Rominger, A. Dreuw, A. S. K. Hashmi, Chem. Eur. J. 2018, 24, 71; i) F. F. Mulks, P. W. Antoni, F. Rominger, A. S. K. Hashmi, Adv. Synth. Catal. 2018, 360, 1810; j) F. F. Mulks, P. W. Antoni, J. H. Gross, J. Graf, J. F. Rominger, A. S. K. Hashmi, J. Am. Chem. Soc. 2019, 141, 4687.

3 a) F. Miege, C. Meyer, J. Cossy, Org. Lett. 2010, 12, 4144; b) F. Miege, C. Meyer, J. Cossy, Chem. Eur. J. 2012, 18, 7810.

4 E. Seraya, E. Slack, A. Ariafard, B. F. Yates, C. J. T. Hyland, Org. Lett. 2010, 12, 4768

5 a) M. S. Hadfield, A.-L. Lee, Chem. Commun. 2011, 47, 1333 b) P. C. Young, M. S. Hadfield, L. Arrowsmith, K. M. Macleod, R. J. Mudd, J. A. Jordan-Hore, A.-L. Lee, Org. Lett. 2012, 14, 898.

6 a) G. Seidel, R. Mynott, A. Fürstner, Angew. Chem. Int. Ed. 2009, 48, 2510-2513; b) D. Benitez, N. D. Shapiro, E. Tkatchouk, Y. Wang, W. A. Goddard III, F. D. Toste, Nat. Chem. 2009, 1, 482.

7 N. A. Rajabi, M. J. Atashgah, R. BabaAhmadi, C. Hyland, A. Ariafard, J. Org. Chem. 2013, 78, 9553.

8 a) A. Correa, N. Marion, L. Fensterbank, M. Malacria, S. P. Nolan, L. Cavallo, Angew. Chem. Int. Ed. 2008, 47, 718; b) R. K. Shiroodi, V. Gevorgyan, Chem. Soc. Rev. 2013, 42, 4991; c) S. Wang, G. Zhang, L. Zhang, Synlett 2010, 692.

9 a) J. F. Briones, H. M. L. Davies, J. Am. Chem. Soc. 2013, 135, 13314; b) G. Xu, C. Zhu, W. Gu, J. Li, J. Sun, Angew. Chem. Int. Ed. 2015, 54, 883; c) E. López, G. Lonzi, L. A. López, Organometallics 2014, 33, 5924; d) G. Lonzi, L. A. López, Adv. Synth. Catal. 2013, 355, 1948; e) J. Barluenga, G. Lonzi, M. Tomás, L. A. López, Chem. Eur. J. 2013, 19, 1573; f)

V. V. Pagar, A. M. Jadhav, R.-S. Liu, J. Am. Chem. Soc. 2011, 133, 20728; g)E. López, G. Lonzi, J. González, L. A. López, Chem. Commun. 2016, 52, 9398; h) D. Zhang, G. Xu, D. Ding, C. Zhu, J. Li, J. Sun, Angew. Chem. Int. Ed. 2014, 53, $11070 ;$ i) B. Herlé, P. M. Holstein and A. M. Echavarren, ACS Catal., 2017, 7, 3668; j) M. Mato, B. Herlé and A. M. Echavarren, Org. Lett., 2018, 20, 4341; k) M. Mato, C. G. Morales and A. M. Echavarren, ChemCatChem, 2019, 11, 53.

$10 \mathrm{In}$ an isolated example, Wang and co-workers reported $\mathrm{Au}(\mathrm{I})$ catalysed cycloisomerisation reactions of cyclopropenes with alkenes, alkynes and allenes tethered to a C3-pendant aminomethyl group. C. Li, Y. Zeng, H. Zhang, J. Feng, Y. Zhang, J. Wang, Angew. Chem. Int. Ed. 2010, 49, 6413.

11 For examples of alkynes undergoing gold-catalysed reactions with tethered furans, see: a) A. S. K. Hashmi, T. M. Frost, J. W. Bats, J. Am. Chem. Soc. 2000, 122, 11553; b) A. S. K. Hashmi, J. P. Weyrauch, M. Rudolph, E. Kurpejović, Angew. Chem. Int. Ed. 2004, 43, 6545; c) A. S. K. Hashmi, P. Haufe, C. Schmid, A. R. Nass, W. Frey, Chem. Eur. J. 2006, 12, 5376; d) A. S. K. Hashmi, M. Rudolph, J. Huck, W. Frey, J. W. Bats, M. Hamzić, Angew. Chem. Int. Ed. 2009, 48, 5848; e) A. S. K. Hashmi, S. Pankajakshan, M. Rudolph, E. Enns, T. Bander, F. Rominger, W. Frey, Adv. Synth. Catal. 2009, 351, 2855; f) A. S. K. Hashmi,
W. Yang, F. Rominger, Angew. Chem. Int. Ed. 2011, 50, 5762; g) A. S. K. Hashmi, T. Häffner, W. Yang, S. Pankajakshan, S. Schäfer, L. Schultes, F. Rominger, W. Frey, Chem. Eur. J. 2012, 18, 10480-6; h) A. S. K. Hashmi, M. Ghanbari, M. Rudolph, F. Rominger, Chem. Eur. J. 2012, 18, 8113.

12 For examples of allenes undergoing gold-catalysed reactions with tethered furans, see: a) B. Trillo, F. López, M. Gulías, L. Castedo, J. L. Mascareñas, Angew. Chem. Int. Ed. 2008, 47, 951; b) Y. Li, M. Dai, Angew. Chem. Int. Ed. 2017, 56, 11624.

13 For selected references, see: a) I. Alonso, H. Faustino, F. López and J. L. Mascareñas, Angew. Chem. Int. Ed. 2011, 50, 11496-11500.; b) B. Trillo, F. López, S. Montserrat, G. Ujaque, L. Castedo, A. Lledós, J. L. Mascareñas, Chem. Eur. J. 2009, 15, 3336; c) F. López, J. L. Mascareñas, F. López, J. L. Mascareñas, Chem. Soc. Rev. 2014, 43, 2904

14 B. W. Gung, D. T. Craft, L. N. Bailey, K. Kirschbaum, Chem. Eur. J. 2010, 16, 639.

15 a) H.-B. Wang, X.-Y. Wang, L.-P. Liu, G.-W. Qin, T.-G. Kang, Chem. Rev. 2015, 115, 2975; b) A. Vasas, J. Hohmann, Chem. Rev. 2014, 114, 8579; c) S.-G. Liao, H.-D. Chen, J.-M. Yue, J. Am. Oil Chem. Soc. 2011, 88, 301.

16 a) A. M. Sarotti, Org. Biomol. Chem. 2018, 16, 944; b) J.-Q. Liu, Y.-F. Yang, X.-Y. Li, E.-Q. Liu, Z.-R. Li, L. Zhou, Y. Li, M.-H. Qiu, Phytochemistry 2013, 96, 265; c) A. Navarro-Vázquez, R. R. Gil, K. Blinov, J. Nat. Prod. 2018, 81, 203.

17 M. F. Roberts, M. Wink, ALKALOIDS: Biochemistry, Ecology, \& Medicinal Applications. Plenum Press: New York, 1998; p 486.

18 A. S. K. Hashmi, Angew. Chem. Int. Ed. 2010, 49, 5232.

19 a) M. Gruit, D. Michalik, K. Krüger, A. Spannenberg, A. Tillack, A. Pews-Davtyan and M. Beller, Tetrahedron, 2010, 66, 33413352. b) M. R. Bhandari, M. Yousufuddin and C. J. Lovely, Org. Lett., 2011, 13, 1382-1385. c) D. D. Vachhani, M. Galli, J. Jacobs, L. Van Meervelt and E. V. Van der Eycken, Chem. Commun., 2013, 49, 7171-7173. d) C. Ferrer and A. M. Echavarren, Angew. Chem. Int. Ed. 2010, 2006, 45, 11051109. e) Y. Lu, X. Du, X. Jia and Y. Liu, Adv. Synth. Catal., 2009, 351, 1517-1522. 